\title{
Effect of prenatal exposure to the endocrine disruptor bisphenol $A$ on mammary gland morphology and gene expression signature
}

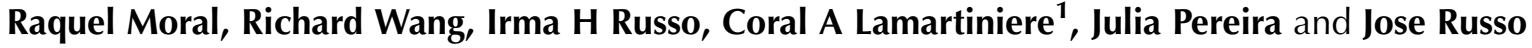 \\ Breast Cancer Research Laboratory, Fox Chase Cancer Center, 333 Cottman Avenue, Philadelphia, Pennsylvania 19111, USA \\ ${ }^{1}$ Department of Pharmacology and Toxicology, University of Alabama at Birmingham, Birmingham, Alabama 35294, USA \\ (Correspondence should be addressed to J Russo; Email: j_russo@fccc.edu)
}

\begin{abstract}
Bisphenol A (BPA), known as an environmental endocrine disruptor, is widely used as a plasticizer. This study aims to investigate whether exposure in utero to BPA alters the architecture, proliferative index, and genomic signature of the rat mammary gland during critical stages of development. Pregnant rats were gavaged with $25 \mu \mathrm{g} \mathrm{BPA} / \mathrm{kg}$ body weight (BW; low-dose group) or $250 \mu \mathrm{g} \mathrm{BPA} / \mathrm{kg} \mathrm{BW}$ (high-dose group) from day 10 post-conception to delivery. Female litters were euthanized at 21, 35, 50, and 100 days, and mammary glands were collected. Analysis of gland morphology was performed from whole-mounted mammary tissue, while proliferative index was determined by detection of bromodeoxyuridine incorporation in the epithelial cells. Genomic profiles were obtained by microarray analysis, and some genes were validated by real-time RT-PCR. BPA exposure induced changes in the mammary gland that were time and dose specific. High-dose exposure resulted in architectural
\end{abstract}

modifications, mainly in the number of undifferentiated epithelial structures of the breast tissue. Proliferative index did not show remarkable differences by the effect of BPA. Low and high doses of BPA changed the gene expression signature of the mammary gland following a different fashion: low dose had the highest effect by 50 days, while high dose had a highest influence on gene expression by 100 days. Both doses presented a significant cluster of up-modulated genes related to the immune system at the age of maximal changes. Moreover, high-dose exposure induced changes in genes related to differentiation suggesting alterations in the normal development of the gland. The increase of undifferentiated structures and the changes in the gene expression profile at different ages suggest that prenatal exposure to BPA can affect the susceptibility of the mammary gland to transformation.

Journal of Endocrinology (2008) 196, 101-112

\section{Introduction}

Breast cancer is an estrogen-dependent malignancy whose incidence is steadily increasing in most western societies and in recently industrialized countries (Althuis et al. 2005). The mammary gland is influenced by many hormones and among them, estrogens are playing a key role in promoting the proliferation of both the normal and the neoplastic epithelium (Russo \& Russo 1997, 1998). Hormones induce developmental changes in the mammary gland that permanently modify the architecture and the biological characteristics of the gland, and changes in the estrogenic environment during critical stages of development can play a role in the future susceptibility to develop breast cancer (Russo \& Russo 1997, 1998). Several lines of evidence in both humans and animal models suggest that in utero exposure to an estrogenic environment increases breast cancer risk later in life (Hilakivi-Clarke et al. 2001, Birnbaum \& Fenton 2003). Moreover, the effect that estrogenic compounds can have on cancer susceptibility depends on the timing of environmental exposure. Prenatal exposure to the non-steroidal estrogen diethylstilbestrol has been associated with increased breast cancer risk (Boylan \& Calhoon 1979), whereas neonatal exposure reduced the incidence of spontaneous (Lamartiniere \& Holland 1992) and induced mammary tumors (Shellabarger \& Soo 1973, Nagasawa et al. 1974). Thus, exposure to estrogenic compounds, especially in utero, acting as endocrine-disrupting chemicals might have potential adverse effects on hormonesensitive organs such as the breast.

Bisphenol A (BPA) is used in the manufacture of polycarbonate plastics and epoxy resins that are found in a wide variety of common products including reusable food and drink containers, baby bottles, protective liners in metal canned foods and beverages, dental composites and sealants, and many other products (Welshons et al. 2006). There is controversial data about the safety of these products. Extensive safety research on BPA has shown that consumer products made with BPA are safe for their intended uses and pose no known risks to human health (Haighton et al. 2002, Gray et al. 2004). On the contrary, a large number of in vivo studies have reported adverse effects concerning low-dose exposures to BPA, even below the current reference dose (Welshons et al. 2006). The differences in the published data can be related to 
the doses used or the developmental period when the compounds were administered.

Several studies have reported high potential of BPA for human exposure, due to an increase in products based on epoxy resins and polycarbonate plastics (Kang et al. 2006). Actually, this xenoestrogen has been found in 95\% of urinary samples in a human reference population in the United States (Calafat et al. 2005), in maternal and fetal plasma, in placental tissue at birth (Ikezuki et al. 2002) and in human colostrum (Kuruto-Niwa et al. 2007). These data suggest accumulation of BPA in early fetuses and significant exposure during the prenatal period. Furthermore, in normal women and women with ovarian dysfunction, there is a positive relationship between the serum levels of BPA and androgens, which may be due to an effect of androgen on the metabolism of BPA (Takeuchi et al. 2006). Although it is difficult to determine doses for experimental studies, the doses chosen for this investigation (25 and $250 \mu \mathrm{g} \mathrm{BPA} / \mathrm{kg}$ body weight $(\mathrm{BW})$ to pregnant rats) were based on reported human exposures, experimental studies in rats, and the US Environmental Protection Agency (US EPA) maximum acceptable dose. Blood sera from human pregnant women have been reported to be $0.46-19 \mu \mathrm{g} / 1$ (Schonfelder et al. 2002, Kuroda et al. 2003, Welshons et al. 2006). Exposure assessments have ranged from $0.2 \mu \mathrm{g} / \mathrm{l}(\mathrm{ng} / \mathrm{g}$ tissue) in human fetal cord serum up to $105 \mu \mathrm{g} / 1$ in human placenta (Kuroda et al. 2003). Within the United States, an exposure of up to $50 \mu \mathrm{g} / \mathrm{kg}$ per day $(50 \mathrm{ppb})$ is considered safe by the US-EPA.

On the other hand, experimental animal models have shown an estrogenic effect of BPA, and thus an endocrinedisrupting action that may have long-term effects on the endocrine system, influencing tumor development later in life (Birnbaum \& Fenton 2003). Prenatal exposure to BPA has been associated with hormonal, morphological, functional, and behavioral anomalies related to reproduction (Adriani et al. 2003), including alterations in the testosterone levels at birth in rats (Tanaka et al. 2006), in brain development in female mice, but not in males (Tando et al. 2007), in rat prostate development (Ramos et al. 2001), in the male and female genital tract (Maffini et al. 2006), and in the tissue organization of the rat and mouse mammary gland (Markey et al. 2001, Munoz-de-Toro et al. 2005). Of special interest, recent data have suggested an effect of BPA on mammary transformation (Durando et al. 2007, Murray et al. 2007). Thus, perinatal exposure to BPA increased the susceptibility to N-nitroso N-methylurea (NMU)-induced preneoplastic lesions during puberty (Durando et al. 2007). Moreover, in utero exposure to BPA induced preneoplastic and neoplastic lesions in the adult mammary gland, even in the absence of any other carcinogenic insult (Murray et al. 2007).

We have previously demonstrated in rodent models that modifications in the susceptibility of the mammary gland to transformation are accompanied by structural and molecular changes of the gland. Pregnancy and pregnancy-mimicking hormonal treatments prevent the development of chemically induced mammary carcinomas (Russo \& Russo 1997, 1998) by the differentiation of the mammary gland that results in elimination of undifferentiated terminal end buds (TEBs) and formation of lobules, resulting in inhibition of cell proliferation and, more importantly, the induction of a specific genomic signature characterized by the up- or downregulation of specific clusters of genes (Russo et al. 2006). Using these parameters as biomarkers for assessing the potential risk of the mammary gland for developing cancer, we have conducted this work with the aim to understand whether in utero exposure to environmentally relevant levels of BPA may affect the developmental pattern and the proliferative activity of the rat mammary gland and, moreover, to identify genomic changes during different stages of the development of this tissue.

\section{Materials and Methods}

\section{Experimental design}

All animal studies were conducted in accordance with the University of Alabama at Birmingham Guidelines for Animal Use and Care. From Charles River (Raleigh, NC, USA), 8-week-old female Sprague-Dawley CD rats (Rattus norvegicus) were bred and maintained on phytoestrogen-free AIN-93G diet (Harlan Texlad, Madison, WS, USA). Pregnant female rats (ten per treatment group) were gavaged with $25 \mu \mathrm{g} \mathrm{BPA} / \mathrm{kg} \mathrm{BW}$ (low-dose group), $250 \mu \mathrm{g}$ BPA/kg BW (high-dose group), or an equivalent volume of sesame oil (control group) on days 10-21 post-conception. The offspring was transferred to surrogate dams immediately after birth. The female offspring were weaned at day 21 and continued on AIN-93G diet until day 70 where they were switched to AIN-93M diet. Females were processed at $21,35 \pm 1,50 \pm 1$, and $100 \pm 2$ days. For the latter three ages, all females were killed in the estrous phase. The fourth abdominal mammary glands were rapidly dissected from live ketamine/ xylazine anesthetized animals. The 'mammary tree' was trimmed free of excess fat and frozen for later microarray analysis. From another set of rats, mammary glands were dissected for whole mount preparation and gland differentiation analysis, and the contralateral mammary gland was paraffin blocked for cell proliferation studies. Eight to ten mammary glands from different animals per group at each time point were used for each of the molecular, morphological, and proliferation analyses.

\section{Mammary gland morphological analysis}

The excised mammary glands were processed for morphological analysis as whole mounts. Tissues were fixed in $10 \%$ neutral-buffered formalin, defatted in acetone, re-hydrated, stained in alum carmine, dehydrated in a series of graded alcohols, cleared in xylene, and coverslipped with mounting media. The total number of epithelial structures (TEBs, terminal ducts (TDs), alveolar buds (ABs), and lobules type 1 (Lob 1)) was determined under an Olympus microscope using a $40 \times$ magnification objective. These structures were 
recognized according to criteria previously established and counted in the zone $\mathrm{C}$, opposite to the nipple, which is the most actively growing area of the mammary gland (Russo \& Russo 1996). Data collected were analyzed using ANOVA and two-tailed unpaired $t$-tests.

\section{Proliferative index analysis}

Animals were injected with bromodeoxyuridine (BrdU) $2 \mathrm{~h}$ before euthanasia. Cycling animals received the BrdU injection while in estrous. The abdominal mammary glands were fixed in $10 \%$ neutral-buffered formalin, embedded in paraffin, and sectioned at $4 \mu \mathrm{m}$ thickness. Tissue sections were mounted on positively charged slides and immunocytochemically reacted with anti-BrdU monoclonal antibody (BioGenex, San Ramon, CA, USA) using an automatic slide stainer (BioGenex). Incorporated BrdU was visualized using the streptavidinbiotin-labeling system with $3,3^{\prime}$-diaminobenzidine (DAB) as a color reaction substrate (BioGenex). The proliferative index was determined quantitatively under Olympus BX40 microscope $(60 \times$ magnification objective) as the percentage of DABpositive cells within specific epithelial structures, i.e., TEBs, TD and ducts, Abs, and Lob 1. Data from different groups were analyzed by ANOVA and unpaired $t$-tests.

\section{Determination of gene expression profile by microarrays}

Total RNA from frozen abdominal mammary glands was extracted by TRIzol reagent (Invitrogen) according to manufacturer's instructions. The quality and the quantity of each sample were individually verified by spectrophotometry using NanoDrop 2.5.4. (NanoDrop Technologies, Wilmingon, DE, USA) and by capillary electrophoresis using Agilent 2100 Bioanalyzer (Agilent Technologies, Palo Alto, CA, USA). The eight samples in each group were then pooled to reduce them to four samples per group.

Fluorescent cRNA probes were prepared using Agilent Low Input RNA Fluorescent Linear Amplification Kit (Agilent Technologies) in the presence of Cy3-dCTP or Cy5-dCTP (Perkin-Elmer, Wellesley, MA, USA), and then purified using RNeasy Mini Kit (Qiagen Inc). Eight picograms of Cy3 and Cy5 from labeled control probe and labeled BPA group probe respectively, were used to hybridize an Agilent 60-mer oligo-microarrays slide containing 22000 features. Slides were hybridized at $60^{\circ} \mathrm{C}$ for $18 \mathrm{~h}$ in SureHyb chambers (Agilent Technologies). Slides were then washed and scanned.

The images obtained were analyzed with Feature extraction software (Agilent Technologies) to verify the quality of the hybridization by the report of the outlier data. The intensity of the spots was measured using ImaGene 5.6 software (BioDiscovery Inc., El Segundo, CA, USA). Spots with pixels with very low or high intensity, or with saturated pixels, were then removed from the defined features and background. Log ratios of the red and green channels were calculated, as well as a $\log$ ratio error and a $P$ value for each feature. These metrics assessed the level of confidence in order to determine whether one gene was or was not differentially expressed in this experiment. For statistical analysis, we used GeneSight 4.1.6 software (BioDiscovery). The lowess method that calculates the normalization curve which measures the potential log ratio bias across the entire range of spot intensities was selected for normalization. We determined the genes with $\geq 1 \cdot 4$-fold differences by confidence analyses at $P<0 \cdot 05$. The methodology used to adjust the $P$ values does not allow the determination of the false discovery rates. The confidence analyzer established confidence levels, beyond which genes were selected as differentially regulated, by pooling the replicate differences from a population together into an empirical distribution of residuals.

We performed functional analysis of the genes obtained as differentially expressed using Protein ANalysis THrough Evolutionary Relationships (PANTHER). The genes were annotated to known function and mapped to PANTHER biological process, molecular function, and biological pathways. The lists of the clusters for differentially expressed genes at different ages and by the different doses of BPA were statistically compared with the $R$. norvegicus genes reference list (NCBI) to look for under- and over-represented functional categories. Each list was compared using the binomial test (Cho \& Campbell 2000) and the Bonferroni correction for multiple testing.

\section{Gene expression analysis by real-time RT-PCR}

Several genes found differentially expressed in the mammary glands of rats exposed prenatally to BPA were chosen to validate gene expression results by quantitative real-time RT-PCR. All RT-PCRs were performed on the ABI Prism 7700 Sequence Detection System (Applied Biosystems, Foster City, CA, USA) using the fluorescent Taqman methodology (TaqMan One Step RT-PCR Master Mix Reagents, Applied Biosystems). Total RNA (100 ng) was used for each reaction in a total volume of $50 \mu \mathrm{l}$ according to the manufacturer's protocol. The thermal cycling conditions comprised $30 \mathrm{~min}$ at $48^{\circ} \mathrm{C}, 10 \mathrm{~min}$ at $95^{\circ} \mathrm{C}$, and 40 cycles of $15 \mathrm{~s}$ denaturation at $95^{\circ} \mathrm{C}$ and 60 s annealing at $60{ }^{\circ} \mathrm{C}$. The end point used in the real-time RT-PCR quantification, $C_{\mathrm{t}}$, was defined as the PCR cycle number at which each assay target passes the threshold. Each gene was normalized using $\beta$-actin as a control gene, and data were analyzed using two-tailed unpaired $t$-test.

\section{Results}

\section{Mammary gland architecture}

The mammary gland architecture was evaluated by quantification of epithelial TDs structures, i.e., TEBs, TDs, ABs, and Lob 1. The total number of these epithelial structures in the zone C of the mammary gland (Russo \& Russo 1996) at different ages of development in the control and BPAexposed rats is shown in Fig. 1. At 21 days, the main epithelial structure of the mammary gland was the TEB, and its number decreased over time in the three groups, whereas the number 

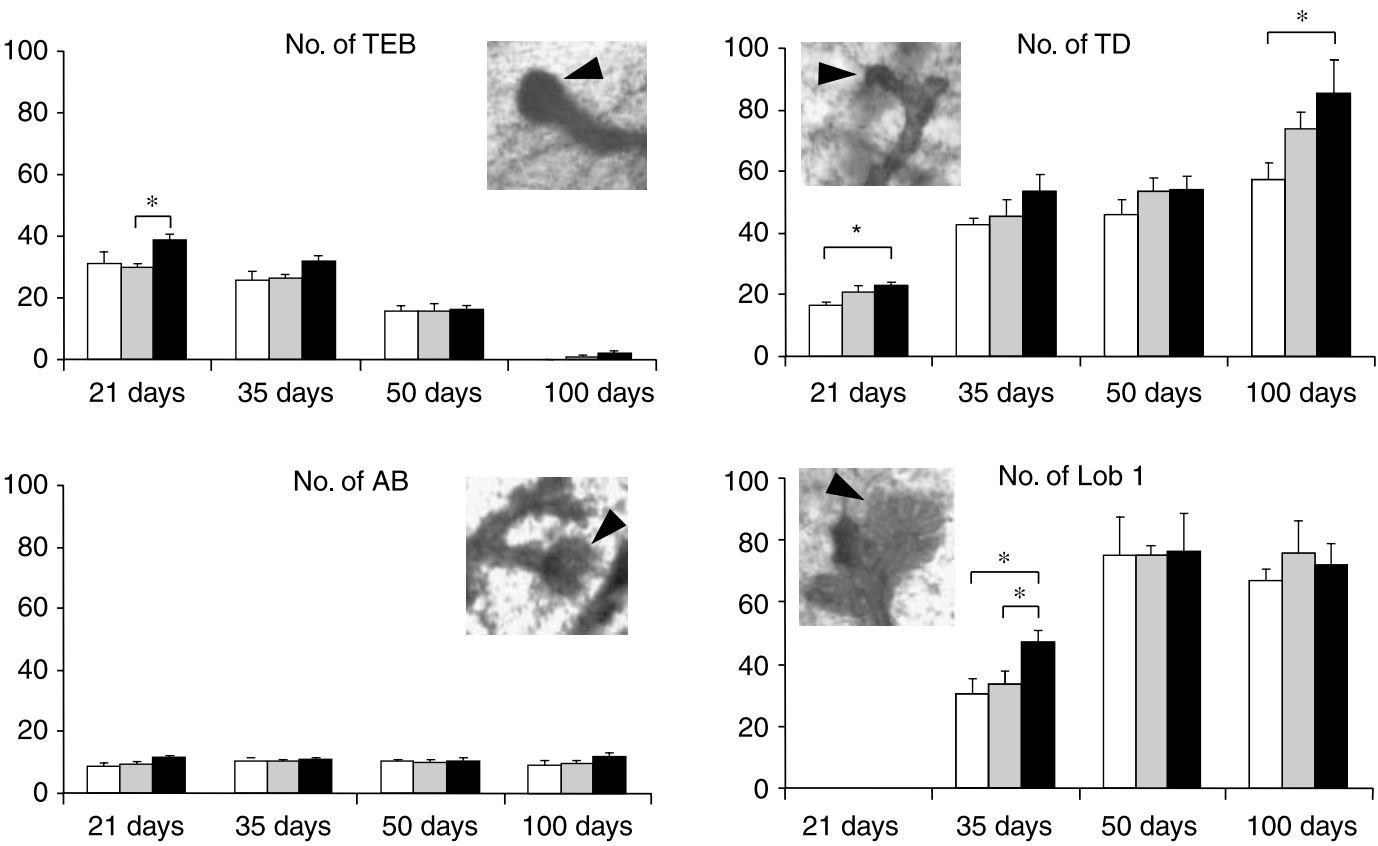

Control $\square$ Low dose $\quad$ High dose

Figure 1 Morphological analyses of the mammary gland. Total number (mean \pm S.E.M.) of TEB, TD, AB, and Lob 1 in the zone $\mathrm{C}$ of the mammary glands from control and BPA-exposed rats at different ages of the development. Representative images of each epithelial structure are shown (Olympus BX40 microscope with $40 \times$ objective). *Significant differences $(P<0 \cdot 05)$.

of TD increased proportionally with age in all groups. The amount of Lob 1 increased from 21 to 50 days.

The number of TEB was significantly increased in the high-dose group related to the low-dose group at 21 days of age. We also observed an increase in the number of TD proportional to BPA dose, being significantly higher in the high-dose group compared with control group at 21 and 100 days. The number of $\mathrm{AB}$ showed little differences over time or in relation to the exposure to BPA. Regarding the lobular structures, the number of Lob 1 was significantly higher in the high-dose group in comparison with low-dose and control groups by 35 days of age (Fig. 1).

\section{Proliferative index}

The proliferative index in the different epithelial structures was evaluated by incorporation of BrdU into the DNA of proliferating cells and immunological detection in paraffin sections of the mammary gland. Comparison of BPA exposed groups with controls did not show major influence of BPA on cell proliferation index (data not shown).

\section{Gene expression profile}

The scatter plots of the microarrays performed from the mammary glands of BPA-exposed rats compared with the controls showed high correlation coefficients $(>0.95)$ between experimental and control conditions at all ages, indicating the high reproducibility of the methodology and that most of the 20000 expression sequences examined were similarly expressed between the treatment groups and the controls (data not shown). We determined the genes with $\geq 0.5 \mathrm{log}$ base 2 differences $(1.4$-fold) at $P<0.05$ (Supplemental Tables 1 and 2 see supplementary data in the online of version of the Journal of Endocrinology at http:// joe.endocrinology-journals.org/content/vol196/issue 1). We are aware of the limitations of this screening methodology in general, and the conditions used in this study in particular, including the statistical analysis chosen and the low cutoff used. Nevertheless, we considered these data of interest as it allowed us the finding of genes that we validated by the more reliable real-time RT-PCR, thus providing an insight into the effects that BPA can have on the mammary gland.

For both treated groups (low and high doses), the number of genes with changes in the gene expression was low at 21 days and lower at 35 days. By 50 days, the number of up-modulated genes increased in both groups, and at 100 days the high-dose group shows the maximum number of modulated genes. Thus, at 21 days, in the low-dose group $(25 \mu \mathrm{g})$, we found 31 genes up-modulated (16 of them known genes) and two known down-modulated genes, one of them being Gad1. In the high-dose group $(250 \mu \mathrm{g})$, we obtained 65 up-regulated genes, 22 of them known and included genes related to cell differentiation. By 35 days of 
age, the number of genes in the low-dose group decreased to two known up-modulated and three down-modulated (one known). At that age, the high-dose group presented 29 up-modulated genes (11 of them known) and 19 downmodulated (with five known genes, including Gad1). At 50 days in the low-dose group, we obtained 189 up-modulated genes, 68 of them known including genes with a role in cell death (Ets1, Ripk3, and Stk17b) or immune function and response to stress (Cd3d, cathepsin E, Ctse, Cd5, and Sod2), and three down-modulated genes (one known, the growth arrest specific 6). The high-dose group had 88 up-modulated sequences ( 40 known genes, some related to differentiation as fatty acid-binding protein $3, F a b p 3$, insulin-like growth factor, Igf2, whey acidic protein, Wap, Tnni2, Pvalb, and $M y l 2$ ) and five down-modulated genes (two of them known, Gad1 and growth arrest-specific gene 6, Gas6). At 100 days, the number of genes found in the low-dose group was reduced to five unknown up-regulated genes and six downregulated sequences (five of them known genes). In the highdose group, we obtained 330 up-modulated genes (114 known) and 91 down-modulated expression sequences (42 known genes). Among the up-regulated genes, we found an important cluster of them related to immune response (Cd3d, Ctse, Cd5, Ltb, Cxcl10, Ccl5, Mefv, Cd2, A2m, and Il1b). Interestingly, at that age, we obtained as down-regulated genes, some that were related to differentiation (casein $\kappa$ (Csn10) and Fhl1) including some that were found as up-modulated by 50 days (Fabp3, Wap, and crystallin $\alpha$-B, Cryab; Supplemental Tables 1 and 2).

\section{Functional analyses}

Functional analysis of the modulated genes was performed using PANTHER (Fig. 2). The gene ontology of the sequences found modulated by the effect of prenatal exposure to BPA revealed that the low-dose group presented significant over-representation of genes with a function in cell proliferation and differentiation, cell communication, signal transduction, immunity, protein metabolism and modification, and apoptosis by 50 days. The high-dose group showed several over-represented functional categories, at 21 days (cell proliferation and differentiation, and cell communication), 50 days (developmental processes), and mainly at 100 days (cell proliferation and differentiation, developmental processes, cell communication, signal transduction, immunity, protein metabolism and modification, apoptosis, and cell adhesion). At this age, muscle development and contraction categories were also over-represented among the down-modulated genes.

\section{Validation of gene expression by real-time RT-PCR}

For the validation of the microarray results, we assessed the gene expression by real-time RT-PCR of genes related to different functions, such as cell communication (Gad1), cell proliferation and growth (Fhl1, Gas6, Ets1, and Igfbp2), response to stress (Cryab, Sod2, and Dnaja1), components of the cytoskeleton (Kbtbd10 and Coro1a, related to cell motility), immunity (Ctse, Cd3d, Cd53, and Slpi), apoptosis (Birc3), and genes related to mammary gland differentiation (Fabp3, Wap, Casn10, and Lalba).

As shown in Fig. 3, real-time RT-PCR confirmed most of the genes found in the microarrays and chosen for further analysis. We observed down-regulation of Gad1 at different times, including some end points where we did not obtain changes by microarrays analysis ( 35 and 50 days of animals exposed to low dose). This gene was significantly downmodulated by effect of low dose at 21,35 , and 50 days, and by effect of high dose at 100 days. We also strongly confirmed the up-regulation of immune system genes (significant up-modulation of Ctse, Cd3d, and Cd53, and a trend in the case of Slpi), mainly at 50 days in the group exposed to low dose and at 100 days in the animals exposed to high dose. Genes related to cell differentiation were found significantly up-regulated in high-dose exposed rats by 50 days (Fabp 3), but downregulated by 100 days (Fabp3, Kbtbd10, Csn10, and Wap). Wap was also found down-modulated in low-dose group by 100 days. Other genes of interest were also significantly modulated, as Gas 6 in low- and high-dose groups by 50 days; Coro $1 a$ by 50 days in low-dose group; Fhlh1, Cryab, and Coro $1 a$ in high-dose group by 100 days (Fig. 3). Sod2 had a discrete and close to significance up-modulation in low-dose group by 50 days. Finally, we did not find significant modulation of Igfbp2, Dnaja1 or Ets1 in low-dose group and Birc3 in high-dose group, by real-time RT-PCR.

\section{Discussion}

In this study, we have investigated the effects of prenatal exposure to BPA on the rat mammary gland at different ages of development. Our data indicate that exposure to this xenobiotic induced subtle but important modifications on the mammary gland that were dose- and time dependant. BPA exposure, mainly to high dose $(250 \mu \mathrm{g})$, induced changes in the number of the most undifferentiated epithelial structures (TEB and TD), together with modifications in the expression of several genes at different ages, long after the end of the exposure. Low dose also modified the gene expression profile of the gland as a function of age.

The effects of BPA on maturation and mammary gland development have previously been investigated with contradictory results, probably due to methodological questions. In concordance with previous reports in mice, with specific detailing regarding the identification of the different morphological components, i.e., TEB, TD, and lobules (Markey et al. 2001, Munoz-de-Toro et al. 2005), we have found changes in the number of these epithelial structures, mainly when BPA is administered in utero at high dose. The main structures affected by BPA exposure are the undifferentiated ones. We have previously demonstrated in rat models that the induction of mammary carcinomas requires that the 

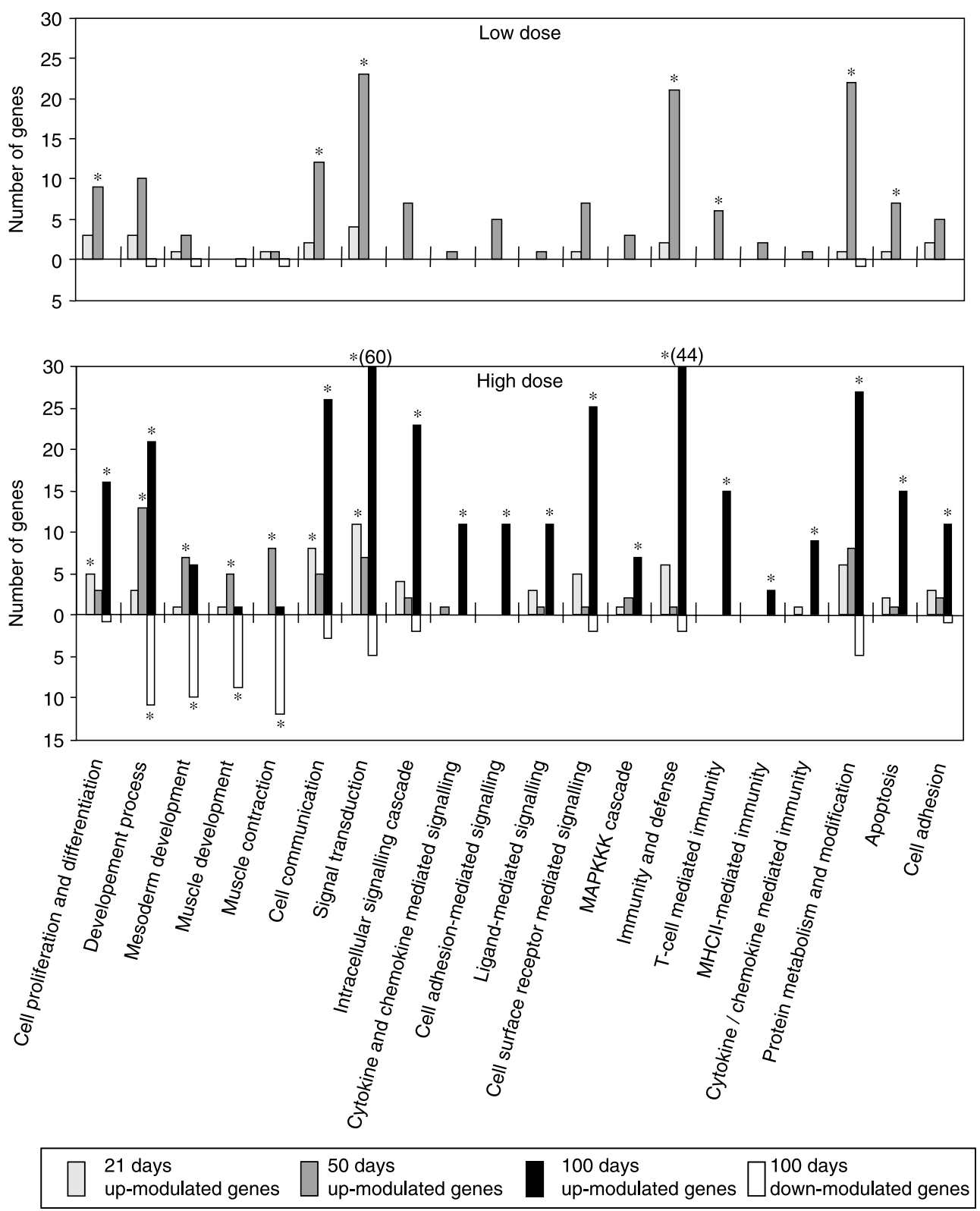

Figure 2 Functional analysis of the genes found differentially expressed in the mammary glands of rats exposed prenatally to low and high doses of BPA. Genes with known function were categorized in biological processes, and the over-represented categories were statistically determined. ${ }^{*} P<0 \cdot 05$.

carcinogen acts on the most undifferentiated structures, the TEB. The higher susceptibility of TEB to neoplastic transformation is attributed to the fact that this is composed of active proliferating epithelium (Russo et al. 1983). Thus, our results suggest subtle but important modifications in the morphology of the mammary gland, as an increase in the number of the structures that are target for carcinogens can have an effect on breast cancer susceptibility later in life.

Russo \& Russo (1980), Tay \& Russo (1981) and Russo et al. (1991) have postulated that the mechanism of pregnancy-induced protection is mediated by the induction of mammary gland differentiation driven by the hormonal milieu of pregnancy, which creates a specific genomic signature in the mammary gland that makes this organ permanently refractory to carcinogenesis. Hence, we have used parameters related to differentiation and proliferation activity as markers to assess modifications in the susceptibility to induced carcinogenesis by effect of BPA exposure. On the other hand, the protective effect of parity has also been proposed to be caused by persistent changes in circulating 

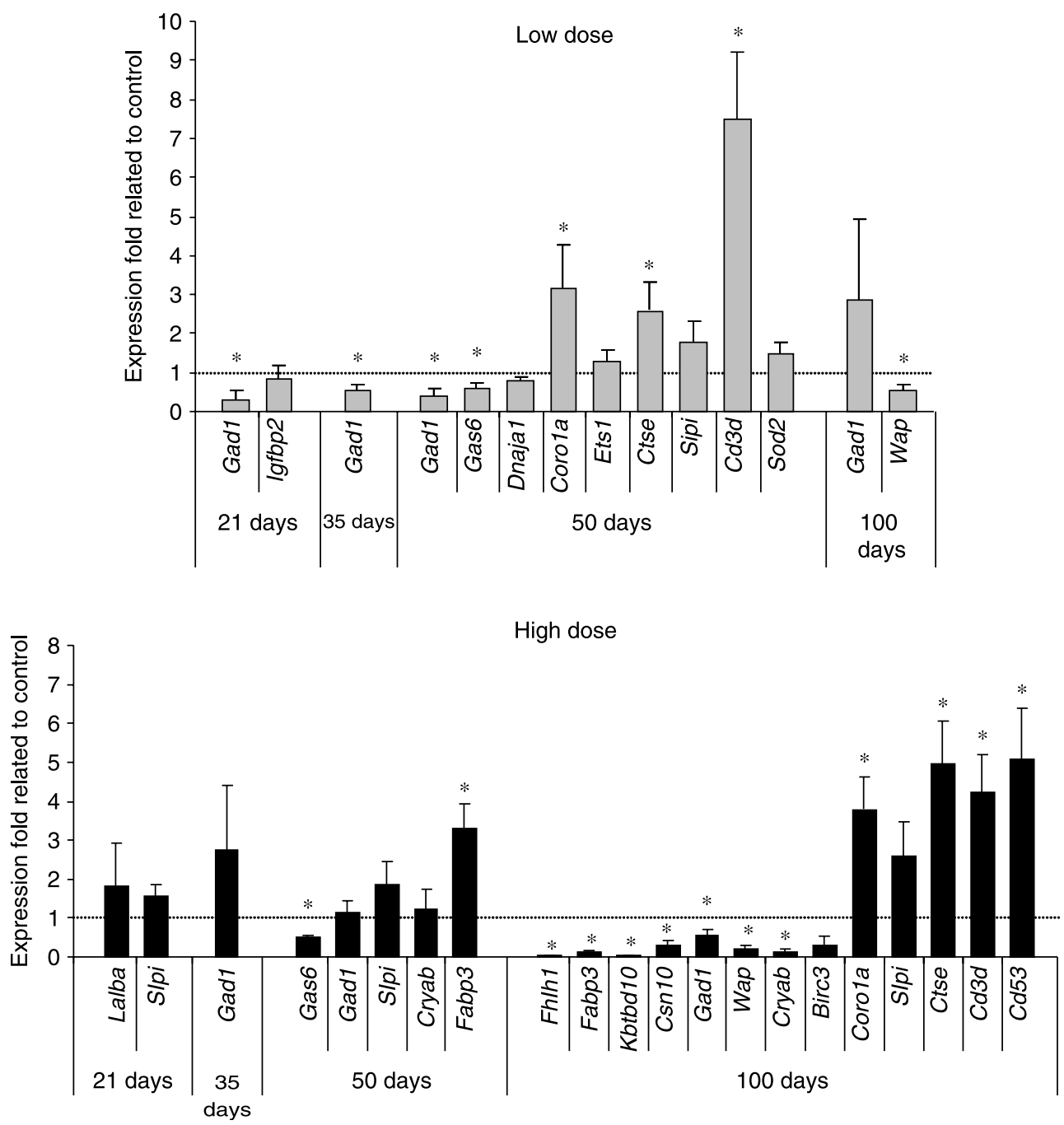

Figure 3 Gene expression analysis by real-time RT-PCR in mammary glands from rats exposed to low and high doses of BPA. Histograms show mean fold expression (mean \pm S.E.M.) related to the mean of the control group (dotted line). *Significant differences related to control group $(P<0 \cdot 05)$.

hormones or growth factors rather than local effects on the mammary gland (Thordarson et al. 1995, Sivaraman \& Medina 2002). Other authors have proposed that the changes occurring in the mammary gland that affect its resistance to transformation, occur during the process of involution that follows pregnancy and lactation by eliminating pre-malignant cells or cells that are particularly susceptible to oncogenic transformation, thus avoiding the progression to an invasive state (Yang et al. 1999, Reddy et al. 2002, Nandi et al. 2005). This interesting hypothesis is not radically different from the one first proposed by Russo \& Russo (1997) who postulated that the Lob 1 and the TEB found in the breast of nulliparous women or of young virgin rats respectively, had not completed their differentiation into Lob 2, Lob 3, and Lob 4, retaining a high concentration of stem cells called stem cells 1, which are susceptible to undergo neoplastic transformation when exposed to a carcinogenic agent. After the postmenopausal involution of the mammary gland, the architecture of the parous breast is similar to that of the nulliparous breast, containing predominantly Lob 1 composed of stem cell 2, an epithelial cell population that is refractory to transformation. It was further postulated that the degree of differentiation acquired through early pregnancy permanently changes the 'genomic signature' that differentiate the Lob 1 from early parous women from that of nulliparous women, shifting the stem cell 1 to the stem cell 2 that is refractory to carcinogenesis. These cells were called stem cell 2 because after post-lactational involution, the mammary epithelium remains capable of responding with proliferation and differentiation to the stimulus of a new pregnancy; however, these cells are refractory to carcinogenesis, even though they are stimulated to proliferate and to 
regenerate the whole mammary gland. The stem cell 2 is characterized by having a genomic signature that has been induced by the first cycle of differentiation. During the last 8 years, supporting evidence to this hypothesis has been generated by Russo et al. as well as by other researchers. Recent studies by Smith et al. (Wagner et al. 2002, Henry et al. 2004, Boulanger et al. 2005) using transgenic WAP-driven Cre and Rosa 26-fl-stop-fl-LacZ mice provided evidence of a new mammary epithelial cell population that originates from differentiated cells during pregnancy; $5-10 \%$ of this parityinduced epithelium survives post-lactational involution after the first pregnancy. With successive pregnancies, their percentage increases, reaching $60 \%$ of the total epithelium in multiparous females. The parity-induced mammary epithelial cells (PI-MECs) are equivalent to the stem cell 2 postulated by Russo \& Russo (1997), since these cells show capacity for self-renewal and contribute to mammary outgrowth in transplantation studies. PI-MEC can function as alveolar progenitors in subsequent pregnancies, and it is thought that they would be related to differences in response to hormonal stimulation and carcinogenic agents observed between nulliparous and parous females (Wagner et al. 2002, Henry et al. 2004, Boulanger et al. 2005). Several authors have focused on finding molecular changes as a mechanism of the pregnancy-induced protection (Russo \& Russo 1994, 2004, Ginger et al. 2001, Sivaraman et al. 2001, D'Cruz et al. 2002, Ginger \& Rosen 2003, Medina \& Kittrell 2003, Medina 2004). These changes in the genomic signature induced by physiological process like pregnancy have significant relevance with the novel observation from our studies relating that prenatal exposure to low and high doses of BPA induced differences in the gene expression of the mammary glands, which were time- and dose specific. The prenatal exposure to the low dose $(25 \mu \mathrm{g})$ induced the highest number of modulated genes by 50 days, which is the age of highest susceptibility of the rat mammary gland to chemically induced carcinogenesis (Russo \& Russo 1997). On the other hand, the prenatal exposure to high dose $(250 \mu \mathrm{g})$ resulted in an increasing number of modulated genes to a maximum by 100 days. Taken together, our results have indicated a higher effect with higher dose of BPA (e.g., the histoarchitectural changes or the modifications in gene expression by 100 days). However, the effect on gene expression profile at 50 days was more evident with the exposure to low dose. In the literature, BPA has shown either a dose-response effect (Yoshino et al. 2004) or an inverted U-dose response (Takai et al. 2000), depending on the experimental model studied. Our results by 50 days can be related to the profound changes that the mammary gland is facing at that age, resulting from an intense hormonal activity (Russo \& Russo 1997). Low dose may be inducing changes that, although more subtle than high dose, can be magnified in the period of high hormonal activity. These modifications could be related to epigenetic changes in the mammary gland stem cells, which can be manifested during differentiation.
Interestingly, in both experimental conditions (low and high doses), the age with the maximal number of modulated genes presented an important cluster related to immune response, including Ctse (Sealy et al. 1996), Cd53 (Tohami et al. 2004), Cd3d (Fischer et al. 2005), or secretory leukocyte peptidase inhibitor (Slpi; King et al. 2003). In addition, the cytoskeletal protein Coronin-1A (Coro1a), also found up-modulated by effect of low and high doses at 50 and 100 days respectively, has been reported to play a role in $\mathrm{T}$ cell differentiation/activation events ( $\mathrm{Nal}$ et al. 2004). We have verified the increased expression levels of some of those genes, such as Ctse, Cd3d, Cd53, and Coro1a and we also observed moderate up-modulation of Slpi by real-time RT-PCR. It has long been known that the immune system is regulated by the gonadal steroids, such as estrogen, androgen, and progesterone (Grossman 1984), and modulation by estradiol of Ctse (Gladson et al. 1998) and Slpi (Chen et al. 2004) has been reported. These results are in accordance with others reported in the literature, as there is evidence that administration of BPA in mice has a modulating activity on immune response (Youn et al. 2002, Lee et al. 2003, Yamashita et al. 2003). Prenatal exposure in mice also increased immune responses in adulthood (Yoshino et al. 2004). Our results also indicate that exposure to BPA has an effect on immune surveillance long after the end of the treatment. Considering that the expression of some of those genes has been found modified in different tumors or tumor cell lines (Sealy et al. 1996, King et al. 2003, Yunta \& Lazo 2003, Kluger et al. 2005, Wild et al. 2005), we cannot rule out the possibility that changes in their expression can affect the susceptibility to transformation.

We also found differences in genes related to differentiation depending of the age tested, mainly in animals exposed to high dose of BPA. Interestingly, the high dose induced up-regulation of breast differentiation markers at 50 days but down-regulation by 100 days. That is the case of Fabp3, which has been related to mammary differentiation (Yang et al. 1994, Hu et al. 1997). This gene is an identical homolog to mammary-derived growth inhibitor (MDGI), a breast tumor growth suppressor gene capable of inhibiting tumor cell proliferation (Huynh et al. 1995). In previous studies, in human breast tissue, we observed a highly MDGI expression in the most differentiated lobular structures (Lob 4), and that its expression was silenced in breast cancer progression ( $\mathrm{Hu}$ et al. 1997). We also observed this kind of change in the expression of the mammary differentiation marker Wap (Dandekar et al. 1982). Other differentiation markers were found down-modulated by 100 days, as cas 10 and other genes like kelch repeat and BTB (POZ) domain containing 10 (Kbtbd10), Cryab that has been reported as down-modulated in breast tumors and metastasis (Seitz et al. 2006); and four and a half LIM domains 1 (Fhl1), suggested as a tumor suppressor gene (Shen et al. 2006). Thus, the observed changes in the expression of these genes by effect of high dose of BPA suggest a molecular context in the mammary glands compatible with a lower degree of differentiation. The lower degree of differentiation markers by 100 days in the high-dose group is 
in accordance with the increase in the undifferentiated structures by this age, as TDs.

On the other hand, some genes related to growth were modulated by the effect of BPA exposure. Gas6, which exerts an anti-apoptotic and proliferative action (Hafizi \& Dahlback 2006), was down-regulated in both low- and high-dose groups by 50 days of age. Gas 6 has been reported to be induced by estrogen in normal and tumor mammary epithelial cells (Mo et al. 2007). Fhl1, also related to cell growth, was down-modulated in the mammary glands from 100-day-old rats prenatally exposed to high dose. As mentioned above, this gene is suggested to be a tumor suppressor gene (Shen et al. 2006). Other genes of interest were related to important cellular functions, like stress response. That is the case for Cryab, down-modulated by 100 days. Cryab is a small heat shock protein that seems to modulate filament organization under conditions of physiological stress (Head \& Goldman 2000). Moreover, Cryab has been found down-modulated in breast tumors and metastasis (Seitz et al. 2006) and its deregulation in our experimental tissues can be related to changes in the differentiation status of the mammary gland by the effect of high dose of BPA. Finally, we found significant down-regulation of Gad1 at different ages. The enzyme encoded by the gene Gad 1 is responsible for catalyzing the production of $\gamma$-aminobutyric acid (GABA). Estrogen modulates mRNA and protein expression of GAD1 and GAD2 in adult rat hippocampus concomitantly with negative and positive controls of luteinizing hormone release (Wagner et al. 2001, Nakamura et al. 2004), and GAD1 gene expression changes in discrete regions of the rostral preoptic area during estrous cycle and with age (Cashion et al. 2004). Studies in nonhuman primates also reported the role of Gad1 in control of puberty (Kasuya et al. 1999). GABAergic system is also involved in hormonal regulation and pathogenesis of breast cancer (Opolski et al. 2000) and other types of neoplasia (Matuszek et al. 2001, Azuma et al. 2003, Moon et al. 2004). These lines of evidence suggest that, although the function that Gad1 plays in the mammary gland is unknown, a long-term down-regulation in such tissue by effect of BPA exposure can have an effect in the physiopathology of that gland.

To our knowledge, this is the first microarray analysis of BPA effect in breast cells in vivo, and few studies have addressed the effects of this xenoestrogen in mammary cells in vitro. Estradiol and BPA induced transcriptional changes in estrogen responsive human breast cancer cells derived from the MCF-7 cell line. In accordance with our results, several genes with a role in growth and development were modulated exclusively by BPA, but not by estradiol (Singleton et al. 2006). Human MCF-7 and T47D mammary carcinoma cells have been described to change their transcriptional profile in response to several compounds, including estradiol, BPA, and genistein. These natural and synthetic estrogenic compounds showed a high degree of similarity inducing changes in the expression profile, including up-regulation of genes related to cell division, growth, inhibition of apoptosis, transcription, signal transduction, or adhesion (Buterin et al. 2006). According to the estrogenic activity reported for BPA, the effects observed in our study can be mediated through the estrogen receptors. Even the differences described regarding the genes activated by estradiol, and BPA can be related to the differential ability of each ER ligand to recruit specific coactivator sets (Singleton et al. 2006). However, ER-independent mechanisms also have to be considered. Actually, BPA can modulate gene expression in estrogen-insensitive ER-null C4-12 cell line (Singleton et al. 2004). BPA has been described to strongly bind the human estrogen-related receptor $\gamma$, which has an exceptionally broad specificity of DNA sequence recognition and is strongly expressed in the brain during development (Takayanagi et al. 2006). Other studies have also indicated the potential of BPA to disrupt thyroid hormone action (Zoeller et al. 2005).

In conclusion, BPA exposure induced changes in the mammary gland that were time- and dose specific. Both doses tested modified the gene expression signature of this tissue, with the higher number of up-modulated genes at 50 days in the low-dose group, while the high-dose group presented the maximum gene expression changes by 100 days. Functional analyses of the differentially expressed genes revealed that the genes modified by both doses had similar roles. An important cluster of up-regulated genes had a function in immunity and defense. The morphological study also indicated a higher number of undifferentiated structures by effect of high-dose exposure. Moreover, in these groups, the gene expression of several differentiation markers and cytoskeleton-related genes was found up- or down-modulated when compared with control depending on the age tested. This data suggest a 'shift' in the normal development of the mammary gland, pointing to the importance of the status of differentiation of the gland if affected by a carcinogen. Recent evidence has shown an increase the susceptibility of the mammary gland to transformation by effect of BPA (Durando et al. 2007, Murray et al. 2007). The changes that we have observed in the expression of genes related to immune system, proliferation and differentiation, growth or response to stress, among others, can be one of the mechanisms by which BPA may change such susceptibility.

\section{Acknowledgements}

This publication was made possible by the Breast Cancer and the Environment Research Centers grant number U01 ES/CA 12771 from the National Institute of Environmental Health Sciences (NIEHS), and the National Cancer Institute (NCI), NIH, DHHS. Its contents are solely the responsibility of the authors and do not necessarily represent the official views of the NIEHS or NCI, NIH. The authors declare that there is no conflict of interest that would prejudice the impartiality of this scientific work. 


\section{References}

Adriani W, Seta DD, Dessi-Fulgheri F, Farabollini F \& Laviola G 2003 Altered profiles of spontaneous novelty seeking, impulsive behavior, and response to D-amphetamine in rats perinatally exposed to bisphenol A. Environmental Health Perspectives 111 395-401.

Althuis MD, Dozier JM, Anderson WF, Devesa SS \& Brinton LA 2005 Global trends in breast cancer incidence and mortality 1973-1997. International Journal of Epidemiology 34 405-412.

Azuma H, Inamoto T, Sakamoto T, Kiyama S, Ubai T, Shinohara Y, Maemura K, Tsuji M, Segawa N, Masuda H et al. 2003 Gamma-aminobutyric acid as a promoting factor of cancer metastasis; induction of matrix metalloproteinase production is potentially its underlying mechanism. Cancer Research $\mathbf{6 3}$ 8090-8096.

Birnbaum LS \& Fenton SE 2003 Cancer and developmental exposure to endocrine disruptors. Environmental Health Perspectives 111 389-394.

Boulanger CA, Wagner KU \& Smith GH 2005 Parity-induced mouse mammary epithelial cells are pluripotent, self-renewing and sensitive to TGF-beta1 expression. Oncogene 24 552-560.

Boylan ES \& Calhoon RE 1979 Mammary tumorigenesis in the rat following prenatal exposure to diethylstilbestrol and postnatal treatment with 7,12dimethylbenz[a]anthracene. Journal of Toxicology and Environmental Health $\mathbf{5}$ 1059-1071.

Buterin T, Koch C \& Naegeli H 2006 Convergent transcriptional profiles induced by endogenous estrogen and distinct xenoestrogens in breast cancer cells. Carcinogenesis 27 1567-1578.

Calafat AM, Kuklenyik Z, Reidy JA, Caudill SP, Ekong J \& Needham LL 2005 Urinary concentrations of bisphenol A and 4-nonylphenol in a human reference population. Environmental Health Perspectives 113 391-395.

Cashion AB, Smith MJ \& Wise PM 2004 Glutamic acid decarboxylase 67 GAD67 gene expression in discrete regions of the rostral preoptic area change during the oestrous cycle and with age. Journal of Neuroendocrinology 16 711-716.

Chen D, Xu X, Cheon YP, Bagchi MK \& Bagchi IC 2004 Estrogen induces expression of secretory leukocyte protease inhibitor in rat uterus. Biology of Reproduction 71 508-514.

Cho RJ \& Campbell MJ 2000 Transcription, genomes, function. Trends in Genetics 16 409-415.

Dandekar AM, Robinson EA, Appella E \& Qasba PK 1982 Complete sequence analysis of cDNA clones encoding rat whey phosphoprotein: homology to a protease inhibitor. PNAS 79 3987-3991.

D'Cruz CM, Moody SE, Master SR, Hartman JL, Keiper EA, Imielinski MB, Cox JD, Wang JY, Ha SI \& Keister BA 2002 Persistent parity-induced changes in growth factors, TGF- $\beta 3$, and differentiation in the rodent mammary gland. Molecular Endocrinology 16 2034-2051.

Durando M, Kass L, Piva J, Sonnenschein C, Soto AM, Luque EH \& Munoz-de-Toro M 2007 Prenatal bisphenol A exposure induces preneoplastic lesions in the mammary gland in Wistar rats. Environmental Health Perspectives 115 80-86.

Fischer A, de Saint Basile G \& Le Deist F 2005 CD3 deficiencies. Current Opinion in Allergy and Clinical Immunology 5 491-495.

Ginger MR \& Rosen JM 2003 Pregnancy-induced changes in cell-fate in the mammary gland. Breast Cancer Research 5 192-197.

Ginger MR, Gonzalez-Rimbau MF, Gay JP \& Rosen JM 2001 Persistent changes in gene expression induced by estrogen and progesterone in the rat mammary gland. Molecular Endocrinology 15 1993-2009.

Gladson M, Srinivasan N, Malini T, Arunakaran J, Aruldhas MM \& Govindarajulu P 1998 Interaction of estradiol, progesterone and corticosterone on uterine connective tissue degrading enzymes. Endocrine Research 24 89-103.

Gray GM, Cohen JT, Cunha G, Hughes C, McConnell EE, Rhomberg L, Sipes IG \& Mattison D 2004 Weight of the evidence evaluation of low-dose reproductive and developmental effects of bisphenol A. Human and Ecological Risk Assessment 10 875-921.

Grossman CJ 1984 Regulation of the immune system by sex steroids. Endocrine Reviews 5 435-455.

Hafizi S \& Dahlback B 2006 Signalling and functional diversity within the Axl subfamily of receptor tyrosine kinases. Cytokine and Growth Factor Reviews 17 295-304.
Haighton LA, Hlywka JJ, Doull J, Kroes R, Lynch BS \& Munro IC 2002 An evaluation of the possible carcinogenicity of bisphenol A to humans. Regulatory Toxicology and Pharmacology 35 238-254.

Head MW \& Goldman JE 2000 Small heat shock proteins, the cytoskeleton, and inclusion body formation. Neuropathology and Applied Neurobiology $\mathbf{2 6}$ 304-312.

Henry MD, Triplett AA, Oh KB, Smith GH \& Wagner KU 2004 Parityinduced mammary epithelial cells facilitate tumorigenesis in MMTV-neu transgenic mice. Oncogene 23 6980-6985.

Hilakivi-Clarke L, Cho E, deAssis S, Olivo S, Ealley E, Bouker KB, Welch JN, Khan G, Clarke R \& Cabanes A 2001 Maternal and prepubertal diet, mammary development and breast cancer risk. Journal of Nutrition 131 154S-157S.

Hu YF, Russo IH, Ao X \& Russo J 1997 Mammary derived growth inhibitor MDGI cloned from human breast epithelial cells is expressed in fully differentiated lobular structures. International Journal of Oncology 11 5-11.

Huynh HT, Larsson C, Narod S \& Pollak M 1995 Tumor suppressor activity of the gene encoding mammary-derived growth inhibitor. Cancer Research $552225-2231$.

Ikezuki Y, Tsutsumi O, Takai Y, Kamei Y \& Taketani Y 2002 Determination of bisphenol A concentrations in human biological fluids reveals significant early prenatal exposure. Human Reproduction 17 2839-2841.

Kang JH, Kondo F \& Katayama Y 2006 Human exposure to bisphenol A. Toxicology 226 79-89.

Kasuya E, Nyberg CL, Mogi K \& Terasawa E 1999 A role of gamma-amino butyric acid GABA and glutamate in control of puberty in female rhesus monkeys: effect of an antisense oligodeoxynucleotide for GAD67 messenger ribonucleic acid and MK801 on luteinizing hormone-releasing hormone release. Endocrinology 140 705-712.

King AE, Morgan K, Sallenave JM \& Kelly RW 2003 Differential regulation of secretory leukocyte protease inhibitor and elafin by progesterone. Biochemical and Biophysical Research Communications 310 594-599.

Kluger HM, Chelouche Lev D, Kluger Y, McCarthy MM, Kiriakova G, Camp RL, Rimm DL \& Price JE 2005 Using a xenograft model of human breast cancer metastasis to find genes associated with clinically aggressive disease. Cancer Research 65 5578-5587.

Kuroda N, Kinoshita Y, Sun Y, Wada M, Kishikawa N, Nakashima K, Makino T \& Nakazawa H 2003 Measurement of bisphenol A levels in human blood serum and ascitic fluid by HPLC using a fluorescent labeling reagent. Journal of Pharmaceutical and Biomedical Analysis 30 1743-1749.

Kuruto-Niwa R, Tateoka Y, Usuki Y \& Nozawa R 2007 Measurement of bisphenol A concentrations in human colostrum. Chemosphere 66 1160-1164.

Lamartiniere CA \& Holland MB 1992 Neonatal diethylstilbestrol prevents spontaneously developing mammary tumors. In Proceedings of the First International Symposium on Hormonal Carcinogenesis, pp 305-308. Eds JJ Li, S Nandi \& SA Li. New York: Springer-Verlag.

Lee MH, Chung SW, Kang BY, Park J, Lee CH, Hwang SY \& Kim TS 2003 Enhanced interleukin-4 production in $\mathrm{CD}^{4+} \mathrm{T}$ cells and elevated immunoglobulin $\mathrm{E}$ levels in antigen-primed mice by bisphenol $\mathrm{A}$ and nonylphenol, endocrine disruptors: involvement of nuclear factor-AT and $\mathrm{Ca}^{2+}$. Immunology 109 76-86.

Maffini MV, Rubin BS, Sonnenschein C \& Soto AM 2006 Endocrine disruptors and reproductive health: the case of bisphenol-A. Molecular and Cellular Endocrinology 254-255 179-186.

Markey CM, Luque EH, Munoz De Toro M, Sonnenschein C \& Soto AM 2001 In utero exposure to bisphenol A alters the development and tissue organization of the mouse mammary gland. Biology of Reproduction 65 1215-1223.

Matuszek M, Jesipowicz M \& Kleinrok Z 2001 GABA content and activity in gastric cancer. Medical Science Monitor 7 377-381.

Medina D 2004 Breast cancer: the protective effect of pregnancy. Clinical Cancer Research 10 380S-384S.

Medina D \& Kittrell FS 2003 p53 function is required for hormone-mediated protection of mouse mammary tumorigenesis. Cancer Research 63 6140-6143.

Mo R, Tony Zhu Y, Zhang Z, Rao SM \& Zhu YJ 2007 GAS6 is an estrogeninducible gene in mammary epithelial cells. Biochemical and Biophysical Research Communications 353 189-194. 
Moon MS, Cho EW, Byun HS, Jung IL \& Kim IG 2004 GAD 67 KD antisense in colon cancer cells inhibits cell growth and sensitizes to butyrate and $\mathrm{pH}$ reduction and $\mathrm{H} 2 \mathrm{O} 2$ and gamma-radiation. Archives of Biochemistry and Biophysics 430 229-236.

Munoz-de-Toro M, Markey CM, Wadia PR, Luque EH, Rubin BS, Sonnenschein C \& Soto AM 2005 Perinatal exposure to bisphenol-A alters peripubertal mammary gland development in mice. Endocrinology 146 $4138-4147$.

Murray TJ, Maffini MV, Ucci AA, Sonnenschein C \& Soto AM 2007 Induction of mammary gland ductal hyperplasias and carcinoma in situ following fetal bisphenol A exposure. Reproductive Toxicology 23 383-390.

Nagasawa H, Yanai R, Shodono M, Nakamura T \& Tanabe Y 1974 Effect of neonatally administered estrogen or prolactin on normal and neoplastic mammary growth and serum estradiol-17 beta level in rats. Cancer Research 34 2643-2646.

Nakamura NH, Rosell DR, Akama KT \& McEwen BS 2004 Estrogen and ovariectomy regulate mRNA and protein of glutamic acid decarboxylases and cation-chloride cotransporters in the adult rat hippocampus. Neuroendocrinology 80 308-323.

Nal B, Carroll P, Mohr E, Verthuy C, Da Silva MI, Gayet O, Guo XJ, He HT, Alcover A \& Ferrier P 2004 Coronin-1 expression in T lymphocytes: insights into protein function during $\mathrm{T}$ cell development and activation. International Immunology 16 231-240.

Nandi S, Guzman RC, Thordarson G \& Rajkumar L 2005 Estrogen can prevent breast cancer by mimicking the protective effect of pregnancy. In Hormonal Carcinogenesis IV, pp 153-165. Eds JJ Li, SA Li \& A LlombartBosch. New York: Springer.

Opolski A, Mazurkiewicz M, Wietrzyk J, Kleinrok Z \& Radzikowski C 2000 The role of GABA-ergic system in human mammary gland pathology and in growth of transplantable murine mammary cancer. Journal of Experimental and Clinical Cancer Research 19 383-390.

Ramos JG, Varayoud J, Sonnenschein C, Soto AM, Munoz De Toro M \& Luque EH 2001 Prenatal exposure to low doses of bisphenol A alters the periductal stroma and glandular cell function in the rat ventral prostate. Biology of Reproduction 65 1271-1277.

Reddy M, Nguyen S, Farjamrad F, Laxminarayan S, Lakshmanaswamy R, Guzman R, Yang J \& Nandi S 2002 Short-term hormone treatment with pregnancy levels of estradiol prevents mammary carcinogenesis by preventing promotion of carcinogen initiated cells. Proceedings of the 93rd American Association for Cancer Research Annual Meeting 431964.

Russo J \& Russo IH 1980 Influence of differentiation and cell kinetics on the susceptibility of the rat mammary gland to carcinogenesis. Cancer Research 40 2677-2687.

Russo IH \& Russo J 1994 Role of hCG and inhibin in breast cancer. International Journal of Oncology 4 297-306.

Russo IH \& Russo J 1996 Mammary gland neoplasia in long-term rodent studies. Environmental Health Perspectives 104 938-967.

Russo J \& Russo IH 1997 Role of differentiation in pathogenesis and prevention of breast cancer. Endocrine-Related Cancer 4 7-21.

Russo IH \& Russo J 1998 Role of hormones in cancer initiation and progression. Journal of Mammary Gland Biology and Neoplasia 3 49-61.

Russo IH \& Russo J 2004 Biological and Molecular Basis of Human Breast Cancer. Heidelberg, Germany: Springer-Verlag.

Russo J, Tait L \& Russo IH 1983 Susceptibility of the mammary gland to carcinogenesis. III. The cell of origin of rat mammary carcinoma. American Journal of Pathology 113 50-66.

Russo IH, Koszalka M \& Russo J 1991 Comparative study of the influence of pregnancy and hormonal treatment on mammary carcinogenesis. British Journal of Cancer 64 481-484.

Russo J, Balogh GA, Heulings R, Mailo DA, Moral R, Russo PA, Sheriff F, Vanegas J \& Russo IH 2006 Molecular basis of pregnancy-induced breast cancer protection. European Journal of Cancer Prevention 15 306-342.

Schonfelder G, Wittfoht W, Hopp H, Talsness CE, Paul M \& Chahoud I 2002 Parent bisphenol A accumulation in the human maternal-fetal-placental unit. Environmental Health Perspectives 110 A703-A707.

Sealy L, Mota F, Rayment N, Tatnell P, Kay J \& Chain B 1996 Regulation of cathepsin $\mathrm{E}$ expression during human $\mathrm{B}$ cell differentiation in vitro. European Journal of Immunology 26 1838-1843.
Seitz S, Korsching E, Weimer J, Jacobsen A, Arnold N, Meindl A, Arnold W, Gustavus D, Klebig C, Petersen I et al. 2006 Genetic background of different cancer cell lines influences the gene set involved in chromosome 8 mediated breast tumor suppression. Genes, Chromosomes and Cancer 45 612-627.

Shellabarger CJ \& Soo VA 1973 Effects of neonatally administered sex steroids on 7,12-dimethylbenzaanthracene-induced mammary neoplasia in rats. Cancer Research 33 1567-1569.

Shen Y, Jia Z, Nagele RG, Ichikawa H \& Goldberg GS 2006 SRC uses Cas to suppress Fhl1 in order to promote nonanchored growth and migration of tumor cells. Cancer Research 66 1543-1552.

Singleton DW, Feng Y, Chen Y, Busch SJ, Lee AV, Puga A \& Khan SA 2004 Bisphenol-A and estradiol exert novel gene regulation in human MCF-7 derived breast cancer cells. Molecular and Cellular Endocrinology 221 47-55.

Singleton DW, Feng Y, Yang J, Puga A, Lee AV \& Khan SA 2006 Gene expression profiling reveals novel regulation by bisphenol-A in estrogen receptor-alpha-positive human cells. Environmental Research 100 86-92.

Sivaraman L \& Medina D 2002 Hormone-induced protection against breast cancer. Journal of Mammary Gland Biology and Neoplasia 7 77-92.

Sivaraman L, Conneely OM, Medina D \& O'Malley BW 2001 p53 is a potential mediator of pregnancy and hormone-induced resistance to mammary carcinogenesis. PNAS 98 12379-12384.

Takai Y, Tsutsumi O, Ikezuki Y, Hiroi H, Osuga Y, Momoeda M, Yano T \& Taketani Y 2000 Estrogen receptor-mediated effects of a xenoestrogen, bisphenol A, on preimplantation mouse embryos. Biochemical and Biophysical Research Communications 270 918-921.

Takayanagi S, Tokunaga T, Liu X, Okada H, Matsushima A \& Shimohigashi Y 2006 Endocrine disruptor bisphenol A strongly binds to human estrogenrelated receptor gamma ERRgamma with high constitutive activity. Toxicology Letters 167 95-105.

Takeuchi T, Tsutsumi O, Ikezuki Y, Kamei Y, Osuga Y, Fujiwara T, Takai Y, Momoeda M, Yano T \& Taketani Y 2006 Elevated serum bisphenol A levels under hyperandrogenic conditions may be caused by decreased UDPglucuronosyltransferase activity. Endocrine Journal 53 485-491.

Tanaka M, Nakaya S, Katayama M, Leffers H, Nozawa S, Nakazawa R, Iwamoto T \& Kobayashi S 2006 Effect of prenatal exposure to bisphenol A on the serum testosterone concentration of rats at birth. Human and Experimental Toxicology 25 369-373.

Tando S, Itoh K, Yaoi T, Ikeda J, Fujiwara Y \& Fushiki S 2007 Effects of preand neonatal exposure to bisphenol A on murine brain development. Brain and Development 29 352-356.

Tay LK \& Russo J 1981 Formation and removal of 7,12-dimethylbenz[a]anthracene - nucleic acid adducts in rat mammary epithelial cells with different susceptibility to carcinogenesis. Carcinogenesis 2 1327-1333.

Thordarson G, Jin E, Guzman RC, Swanson SM, Nandi S \& Talamantes F 1995 Refractoriness to mammary tumorigenesis in parous rats: is it caused by persistent changes in the hormonal environment or permanent biochemical alterations in the mammary epithelia? Carcinogenesis $\mathbf{1 6}$ 2847-2853.

Tohami T, Drucker L, Radnay J, Shapira H \& Lishner M 2004 Expression of tetraspanins in peripheral blood leukocytes: a comparison between normal and infectious conditions. Tissue Antigens 64 235-242.

Wagner EJ, Ronnekleiv OK, Bosch MA \& Kelly MJ 2001 Estrogen biphasically modifies hypothalamic GABAergic function concomitantly with negative and positive control of luteinizing hormone release. Journal of Neuroscience 21 2085-2093.

Wagner KU, Boulanger CA, Henry MD, Sgagias M, Hennighausen L \& Smith GH 2002 An adjunct mammary epithelial cell population in parous females: its role in functional adaptation and tissue renewal. Development 129 1377-1386.

Welshons WV, Nagel SC \& vom Saal FS 2006 Large effects from small exposures. III. Endocrine mechanisms mediating effects of bisphenol A at levels of human exposure. Endocrinology 147 S56-S69.

Wild PJ, Herr A, Wissmann C, Stoehr R, Rosenthal A, Zaak D, Simon R, Knuechel R, Pilarsky C \& Hartmann A 2005 Hartmann A Gene expression profiling of progressive papillary noninvasive carcinomas of the urinary bladder. Clinical Cancer Research 11 4415-4429.

Yamashita U, Kuroda E, Yoshida Y \& Sugiura T 2003 Effect of endocrine disrupters on immune responses in vivo. Journal of UOEH 25 365-374. 
Yang Y, Spitzer E, Kenney N, Zschiesche W, Li M, Kromminga A, Muller T, Spener F, Lezius A, Veerkamp JH et al. 1994 Members of the fatty acid binding protein family are differentiation factors for the mammary gland. Journal of Cell Biology 127 1097-1109.

Yang J, Yoshizawa K, Nandi S \& Tsubura A 1999 Protective effects of pregnancy and lactation against $\mathrm{N}$-methyl- $\mathrm{N}$-nitrosourea-induced mammary carcinomas in female Lewis rats. Carcinogenesis 20 623-628.

Yoshino S, Yamaki K, Li X, Sai T, Yanagisawa R, Takano H, Taneda S, Hayashi H \& Mori Y 2004 Prenatal exposure to bisphenol A up-regulates immune responses, including $\mathrm{T}$ helper 1 and $\mathrm{T}$ helper 2 responses, in mice. Immunology 112 489-495.

Youn JY, Park HY, Lee JW, Jung IO, Choi KH, Kim K \& Cho KH 2002 Evaluation of the immune response following exposure of mice to bisphenol A: induction of Th1 cytokine and prolactin by BPA exposure in the mouse spleen cells. Archives of Pharmacological Research 25 946-953.
Yunta M \& Lazo PA 2003 Apoptosis protection and survival signal by the CD53 tetraspanin antigen. Oncogene 22 1219-1224.

Zoeller RT, Bansal R \& Parris C 2005 Bisphenol-A, an environmental contaminant that acts as a thyroid hormone receptor antagonist in vitro, increases serum thyroxine, and alters RC3/neurogranin expression in the developing rat brain. Endocrinology $\mathbf{1 4 6}$ $607-612$.

Received in final form 28 August 2007

Accepted 11 October 2007

Made available online as an Accepted Preprint

11 October 2007 